\title{
The tryptophan kynurenine pathway, neopterin and IL-6 during vulvectomy and abdominal hysterectomy
}

\author{
Jaap Willem Hol ${ }^{*}$, Robert J Stolker ${ }^{1}$, Markus Klimek', Dirk L Stronks ${ }^{1}$ and Durk Fekkes²
}

\begin{abstract}
Background: Surgery has wide ranging immunomodulatory properties of which the mechanism is poorly understood. In order to investigate how different types of surgery influence inflammation, we designed a longitudinal observational study investigating two inflammatory profiles of two separate patient groups undergoing gynaecological operations of differing severity. In addition to measuring the well known inflammatory markers neopterin and IL-6, we also determined the kynurenine/tryptophan ratio.

This study was a prospective, single center, two-armed observational study involving 28 female patients. Plasma levels of tryptophan, kynurenine, neopterin and IL-6 were determined from samples taken at: 24hrs pre-operative, prior to induction, ten minutes before the operation was expected to end, and at 24 and 96 hours post operative in patients undergoing abdominal hysterectomy and vulvectomy.

Results: There were 15 and 13 patients included in the vulvectomy and abdominal hysterectomy groups, respectively. In this study we show that anesthesia and surgery significantly increases the enzyme activity of indoleamine 2, 3 dioxygenase (IDO) as measured by the kynurenine/tryptophan ratio ( $P=0.003)$, while maintaining stable neopterin levels. However, abdominal hysterectomy causes a considerable IL-6 increase $(P<0.001)$.

Conclusion: Surgery and associated anesthesia cause a significant tryptophan level decrease while significantly increasing IDO activity. Both types of surgery produce nearly identical neopterin time curve relationships, with no significant change occurring in either group. However, even though neopterin is unaffected by the severity of surgery, IL-6 responded to surgical invasiveness by revealing a significant increase during abdominal hysterectomy.
\end{abstract}

Keywords: Kynurenine, Tryptophan, Indoleamine 2,3-dioxygenase, Neopterin

\section{Background}

Surgery has wide ranging immunomodulatory properties of which the mechanism is poorly understood [1-3]. In order to better understand the effect of surgery and anesthesia on inflammation, we designed a longitudinal observational study investigating two inflammatory profiles of two separate patient groups undergoing surgery of differing severity while undergoing general anesthesia. In addition to measuring the well known inflammatory markers neopterin and IL-6, we also determined kynurenine and tryptophan.

\footnotetext{
* Correspondence: j.w.hol@erasmusmc.nl

'Department of Anesthesiology, Erasmus Medical Center, PO Box 2040, 3000 CA, Rotterdam, The Netherlands

Full list of author information is available at the end of the article
}

Tryptophan is an essential precursor for serotonin and kynurenine (KYN) [4]. The metabolism of tryptophan to kynurenine is facilitated by the enzyme Indoleamine 2,3 dioxygenase (IDO) [5]. Tryptophan is a vital amino acid for growth. When present in limited amounts it inhibits viral, bacterial and parasitic development. Not only are microorganisms dependent on tryptophan, but T-cell production is also limited by decreased levels [6-8]. Kynurenine, the direct product of tryptophan catabolism has several important physiological and immunosuppressive properties. It regulates immune function by suppressing T-cells and natural killer cells $[9,10]$. Moreover, recent research has found that it contributes to arterial vessel wall relaxation and causes hypotension in a dose dependent manner in systemically inflamed mice [11]. 
The tryptophan kynurenine pathway is regulated by the rate limiting enzyme IDO [5,12] (Figure 1). IDO is made in the vascular endothelial cells and is activated via autocrine and paracrine mechanisms by means of interferon $\gamma$ (IFN $\gamma$ ) released by dendritic and T-cells $[13,14]$. The amount of kynurenine produced relates to its activity $[12,15]$. In addition, IDO contributes to the regulation of blood pressure because it controls the production of kynurenine. This has been demonstrated by the ability of IDO inhibitors to restore normal systolic blood pressure in septic mice [11].

Tryptophan degradation is correlated to neopterin formation; both are stimulated by IFN $\gamma[4,16-19]$. Increased neopterin levels are associated with a pro-inflammatory state mediated by cellular immune system activation [20-22]. It is an endogenous regulator of cytotoxic effects by activated macrophages and a potent enhancer of peroxynitrite [23]. It is a stable molecule eliminated only by the kidney. Higher levels are associated with higher levels of reactive oxygen species and thus serve as an estimate of the oxidative stress caused by the immune system $[24,25]$. Levels of neopterin have been shown to predict the development of septic complications in trauma and post surgical patients. There is a direct correlation between increased neopterin levels and non-survivors [26].

IL-6 is an acute phase pro-inflammatory cytokine capable of being released by macrophages, endothelial cells and T-cells minutes after injury. It is a good marker for acute immune system activation and is accepted as a sensitive early marker of tissue damage with peak serum levels being proportional to the amount of surgical trauma [27-30]. Known to be made within minutes after injury, it is also broken down in a relatively short amount of time [31,32].

Quantifying the above mentioned biochemical substances in blood may give us more insight into peri-operative immunomodulatory processes. Significantly different inflammatory profiles can have wide clinical implications. We hypothesize that more invasive surgery when compared to minor surgery causes significantly more increases in all inflammatory biomarkers measured.

\section{Methods}

\section{Study set-up and inclusion criteria}

This study was a prospective, single centre, two-armed observational study with 28 female patients. The protocol was approved by the Medical Ethics Committee of the Erasmus Medical Centre, Rotterdam (MEC-2008-134). All procedures were performed in accordance with the Helsinki declaration. Informed consent was obtained from all patients.

Inclusion criteria were 1) scheduled for vulvectomy or abdominal hysterectomy, 2) expected surgery duration greater than $0.5 \mathrm{~h}, 3$ ) postoperative hospitalization lasting more than 4 days, 4) age greater than 18 years, 5) ASA (American Society of Anesthesiologists) classification I-III. Exclusion criteria were 1) ASA-classification IV-V, 2) patients unable to speak Dutch, 3) and patients not able to consent. Patients had the right to withdraw from the study at any time. Patients who developed serious adverse side effects were to be withdrawn from the study.

\section{Anesthesia procedure}

All patients received $1.0 \mathrm{mg}$ tablet lorazepam and $100 \mathrm{mg}$ celecoxib (selective COX-2 inhibitor) approximately one

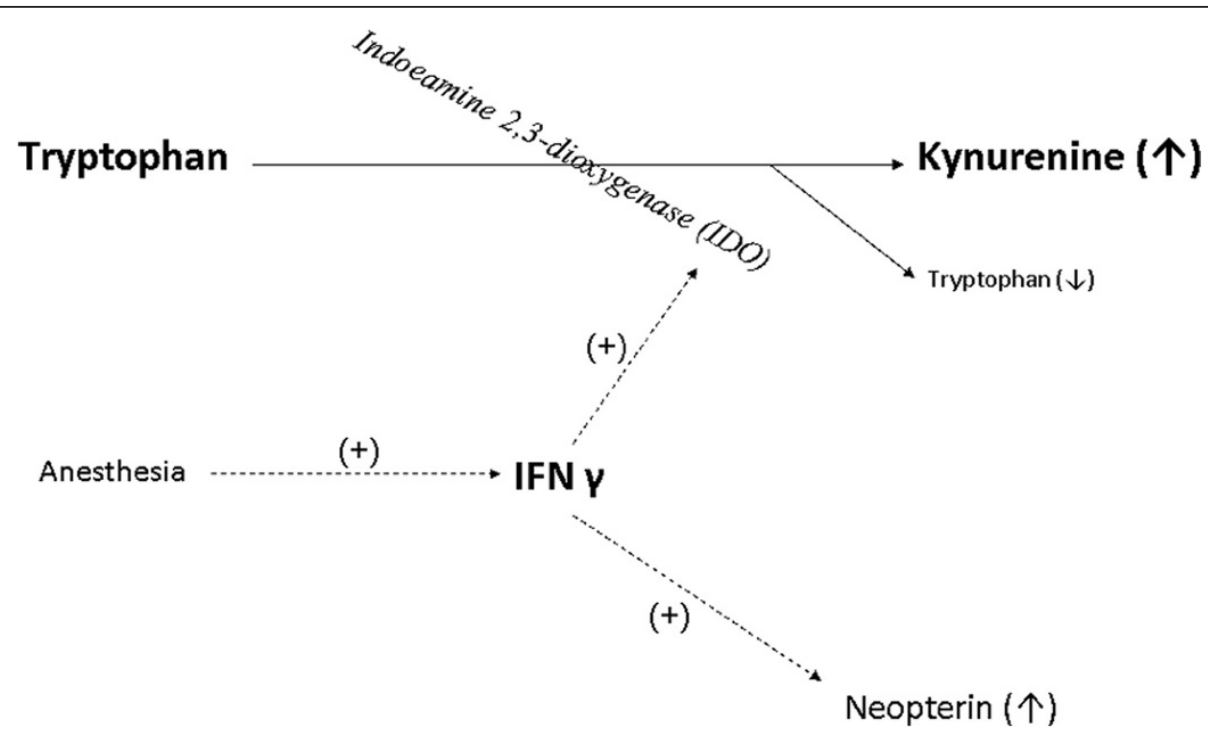

Figure 1 An overview of the tryptophan kynurenine pathway and its relationship with IFN $\gamma$ as well as neopterin. $(+)$ denotes that it activates and or stimulates production. 
hour before surgery. Personal drug regimens were continued during the study. The observational nature of this study allowed the staff anesthesiologist to place an epidural catheter if the anesthesiologist felt it was indicated for adequate post operative pain control. All patients received total intravenous anesthesia, using propofol for sedation and sufentanil for analgesia. Cisatracurium provided muscle relaxation for patients being intubated. Prior to the first incision all patients received antibiotics $(1 \mathrm{~g}$ cefazoline and $500 \mathrm{mg}$ metronidazol).

For all patients the minimum post operative pain control regimen included $4000 \mathrm{mg}$ paracetamol and $200 \mathrm{mg}$ celecoxib per 24 hours. While in the recovery room, morphine was titrated until sufficient pain control was achieved. The daily regimen of paracetamol and celecoxib was continued until patients no longer experienced pain with a VAS greater than four. Patients with an epidural catheter had it removed when the anesthesiologist determined that it was no longer indicated for adequate pain control.

\section{Outcome measures}

Patient demographics, medications used during and after surgery, and duration of surgery were documented. EDTA blood samples $(4 \mathrm{ml})$ were collected for determination of neopterin, kynurenine, and tryptophan at 24 hours pre-operative, right after IV placement prior to induction, ten minutes before anesthesia was expected to end, and at 24 and 96 hours post operative. Plasma was isolated by centrifugation at 2650 gmax for $20 \mathrm{mi}-$ nutes at $20^{\circ} \mathrm{C}$; samples were stored at $-80^{\circ} \mathrm{C}$ until assay. At the same time points blood was collected for preparation of serum used for the measurement of IL-6.

Concentrations of kynurenine and tryptophan were determined via their natural fluorescence using an isocratic, reversed-phase HPLC system (Agilent) and an FP-2020 fluorescence detector (Jasco) as described previously [33]. The analytical column consisted of a $250 \times 2.1 \mathrm{~mm}$ i.d. column packed with $5 \mu \mathrm{m}$ particles of GraceSmart RP-18 (Grace Davison Discovery Sciences), which was protected by a guard cartridge column $(4.0 \times 2.0 \mathrm{~mm}$ i.d. $)$ containing Phenomenex C18 material. An HP ChemStation (Hewlett Packard) was used for data collection and handling. The kynurenine/tryptophan ratio was calculated to estimate the activity of the enzyme indoleamine 2,3 dioxygenase (IDO) [34].

Total neopterin was measured after acid oxidation. Plasma $(0.4 \mathrm{ml})$ was oxidized in $0.1 \mathrm{ml} 1 \mathrm{M}$ trichloroacetic acid and $0.05 \mathrm{ml}$ iodine solution $\left(0.5 \% \mathrm{I}_{2}, 1 \% \mathrm{KI}\right.$ in $0.2 \mathrm{M}$ trichloroacetic acid). After standing for $60 \mathrm{~min}$ under reduced light, excess iodine was reduced by the addition of $20 \mu \mathrm{l}$ of $1 \%$ ascorbic acid solution and the mixture was centrifuged at $12000 \times \mathrm{g}$ for $15 \mathrm{~min}$ at $4^{\circ} \mathrm{C}$. The supernatant $(0.4 \mathrm{ml})$ was transferred to an amber glass vial and $10 \mu \mathrm{l}$ was injected directly onto the analytical column using an HPLC system with an auto sampler and a fluorescence detector as described previously [35].

Enzyme immunoassays for the quantitative determination of human IL-6 were performed with a sandwich ELISA (Pelikine Compact $^{\mathrm{Tm}}$ and additional Pelikine Toolset ${ }^{\mathrm{mm}}$, Sanquin, Amsterdam, The Netherlands) as described previously [36]. Data were calculated as pg/ml. IL-6 Figures were made with Sigma Plot, version 9.0. The results are presented as mean \pm the standard error of the mean (SEM).

\section{Statistical analysis}

Data was analyzed using SPSS for windows, version 16.01. The independent sample t-test was used to compare means for patient demographics (excluding ASA classification) and peri-operative characteristics. The Pearson Chi-square test was used to evaluate differences in ASA classification. The Fisher exact test was used to analyze difference in the type of pain control techniques used between groups (NSAID only, NSAID + Opiates, NSAID + Opiates + Epidural). All data are reported as the mean $\pm \mathrm{SD}$.

Our biochemical data were analyzed using MANOVA. Differences in values measured between the experimental groups across all time points and interaction between experimental groups and time were analyzed using multivariate repeated measures. Experimental group and time were the independent variables. When Mauchly's Test of Sphericity was significant, the Greenhouse-Geisser test was used.

When a significant difference was found between experimental groups a one-way ANOVA test with posthoc multiple comparisons (Bonferroni correction) was used to analyze the relationship between the level of the amino acid from the first pre-operative measurement until 96 hours post operative. The same Bonferroni correction was employed to analyze differences between experimental groups and time. Pairwise comparisons were used to analyze significant differences between longitudinal time points. P-value $<0.05$ was considered statistically significant.

\section{Results}

\section{Demographics}

Twenty eight female patients were included in the study; no patients were withdrawn from the study (Table 1). The vulvectomy group contained 15 patients, while the laparotomy group contained 13 patients. Significant intergroup differences were found for age and ASA classification $(P<0.05)$. Laparotomy patients were younger and had significantly lower ASA scores.

\section{Perioperative characteristics}

Differences in perioperative characteristics were found (Table 2). The abdominal hysterectomy group had a 
Table 1 Patient demographics

\begin{tabular}{lll}
\hline & Vulvectomy & Laparotomy \\
\hline Age (years) & $62 \pm 12$ & $44 \pm 9^{*}$ \\
Height $(\mathrm{cm})$ & $166 \pm 5$ & $167 \pm 6$ \\
Weight $(\mathrm{kg})$ & $71 \pm 10$ & $71 \pm 7$ \\
\hline
\end{tabular}

Data are mean \pm SD.

*Significant difference between groups, $\mathrm{P}<0.001$.

significantly longer operating time $(P=0.002)$, more blood loss $(\mathrm{P}<0.001)$ and correspondingly more fluid replacement in the form of colloids $(\mathrm{P}=0.002)$ and crystalloids $(\mathrm{P}=0.005)$. In addition, significantly more propofol was used ( $\mathrm{P}=0.026)$, however, there was no significant difference in the amount of sufentanil used between groups. One of the patients in the laparotomy group received a blood transfusion with $285 \mathrm{ml}$ of erythrocytes.

There was no significant difference in the amount of post operative morphine, paracetamol or celecoxib given to both groups (Table 3). However, 9 patients from the laparotomy group were given pre-operative epidural catheters while only 3 patients were given one in the vulvectomy group. All epidural catheters were removed by 24 hours post-operative because pain control was found to be adequate.

\section{Plasma tryptophan levels}

Baseline levels of plasma tryptophan 24 hours before surgery did not significantly differ between groups. Throughout time, no significant difference between experimental groups was found. There was however a significant within subject effect over time $(\mathrm{P}<0.001)$ (Figure 2$)$.

Pairwise comparisons reveal a significant decrease between plasma tryptophan measured prior to induction and thirty minutes prior to the end of the operation $(\mathrm{P}<$ 0.001). Following this significant decrease there was a significant increase between plasma tryptophan measured thirty minutes prior to the end of the operation and plasma measured 24 hours post operative $(\mathrm{P}<$ 0.001).

Table 2 Perioperative characteristics

\begin{tabular}{lll}
\hline & Vulvectomy & Laparotomy \\
\hline Propofol during operation $(\mathrm{mg})$ & $1146 \pm 828$ & $1983 \pm 105^{*}$ \\
Operation time $(\mathrm{min})$ & $126 \pm 50$ & $188 \pm 46^{*}$ \\
Blood loss during operation $(\mathrm{ml})$ & $134 \pm 271$ & $959 \pm 335^{\mathrm{a}}$ \\
Colloids during operation $(\mathrm{ml})$ & $170 \pm 242$ & $540 \pm 335^{*}$ \\
Crystalloids during operation $(\mathrm{ml})$ & $1182 \pm 627$ & $1917 \pm 655^{*}$ \\
Sufentanil during operation $(\mu \mathrm{g})$ & $33 \pm 15$ & $37 \pm 14$ \\
Cisatracurium during operation $(\mathrm{mg})$ & $20 \pm 25$ & $68 \pm 18^{*}$ \\
\hline
\end{tabular}

Data are mean \pm SD.

*Significant difference between groups, $\mathrm{P}<0.05$.

aSignificant difference between groups, $\mathrm{P}<0.001$.

\section{Plasma IDO activity, defined by the ratio of tryptophan/ kynurenine}

Baseline levels of plasma IDO activity were not significantly different between both groups. There was a significant within subject effect over time $(P<0.001)$. In addition, a significant difference between experimental groups was found $(\mathrm{P}=0.041)$ (Figure 3 ).

Pairwise comparisons reveal a significant increase in plasma IDO activity measured prior to induction and thirty minutes prior to the end of the operation ( $\mathrm{P}=$ 0.003). Following this significant increase there was a significant decrease between plasma IDO activity measured thirty minutes prior to the end of the operation and plasma measured 24 hours post operative $(\mathrm{P}<0.001)$.

\section{Plasma kynurenine}

Baseline levels of plasma kynurenine were not significantly different between both groups. There was a significant change in plasma kynurenine levels over time for both groups $(\mathrm{P}<0.001)$ as well as a significant difference between experimental groups $(\mathrm{P}=0.032)$. At 96 hours post operative, the vulvectomy group had significantly higher levels of plasma kynurenine than the laparotomy group $(\mathrm{P}=0.028)$ (Figure 3).

Pairwise comparisons reveal a significant decrease in plasma kynurenine measured prior to induction and thirty minutes prior to the end of the operation $(\mathrm{P}<$ 0.001). Following this significant decrease there was a significant increase between thirty minutes prior to the end of the operation and plasma measured 24 hours post operative $(\mathrm{P}<0.041)$.

\section{Plasma neopterin levels}

Baseline levels of plasma neopterin significantly differed between both groups $(\mathrm{P}=0.002)$; the vulvectomy group having much higher levels than the laparotomy group. A significant plasma neopterin level change occurred over time for both groups $(\mathrm{P}<0.033)$. There was also a significant difference between experimental groups $(\mathrm{P}=0.005)$ (Figure 4).

\section{Plasma IL-6 levels}

Baseline levels of plasma IL-6 were not significantly different. A significant plasma IL-6 level change over time occurred for both groups $(\mathrm{P}<0.001)$. There was no significant difference between groups. However, the major abdominal surgery group had produced significantly more IL-6 than the vulvectomy group 30 minutes prior to the end of the operation $(\mathrm{P}<0.001)$ (Figure 5).

\section{Discussion}

In this study we show that surgery and associated anesthesia significantly increase IDO activity, while maintaining stable neopterin levels. However, abdominal 
Table 3 Postoperative characteristics

\begin{tabular}{llllll}
\hline & \multicolumn{2}{l}{ Vulvectomy } & & Laparotomy \\
\cline { 2 - 3 } \cline { 5 - 6 } & $\mathbf{2 4}$ hours post-operative & $\mathbf{9 6}$ hours post-operative & & 24 hours post-operative & $\mathbf{9 6}$ hours post-operative \\
\hline Paracetamol (mg) & $3769 \pm 832$ & $4000 \pm 0$ & $186 \pm 38$ & $3833 \pm 577$ & $4000 \pm 0$ \\
Celecoxib (mg) & $200 \pm 0$ & - & $200 \pm 0$ & $233 \pm 82$ \\
Morphine $(\mathrm{mg})$ & $6 \pm 2$ & & $12 \pm 1$ & - \\
\hline
\end{tabular}

Data are mean \pm SD. Celecoxib (selective COX-2 inhibitor).

hysterectomy causes a major IL-6 increase. Via this longitudinal observational study, we believe we are the first to compare how two well defined surgical interventions of differing severity affect the tryptophan kynurenine pathway and the two inflammatory mediators neopterin and IL-6. It must be stressed, that there are differences in age and ASA-score between the groups. It was not our intention to compare two more or less identical groups. Due to the fact that the higher age and the higher ASA-score are associated with the vulvectomy group while most changes occur in the younger and healthier abdominal hysterectomy group, we can conclude that the observed effects are caused by the procedure and not by comorbidity.
Our tryptophan results show that in both groups stable baseline levels significantly decrease after induction with a significant rebound occurring during the 24 hour period after surgery. This data suggest that tryptophan is being rapidly consumed after induction. Anesthesia has been shown to cause IFN gamma release which in turn activates the enzyme IDO [37-39]. Our results show that there is significant activation $(\mathrm{P}=0.003)$ of the IDO enzyme as suggested by the tryptophan/ kynurenine ratio measured in both groups. During the 24 hours following surgery, however, a significant deactivation of IDO occurs $(\mathrm{P}<0.001)$, although 96 hours after surgery IDO activity returns to pre-operative levels. The significant kynurenine increase seen between the end of

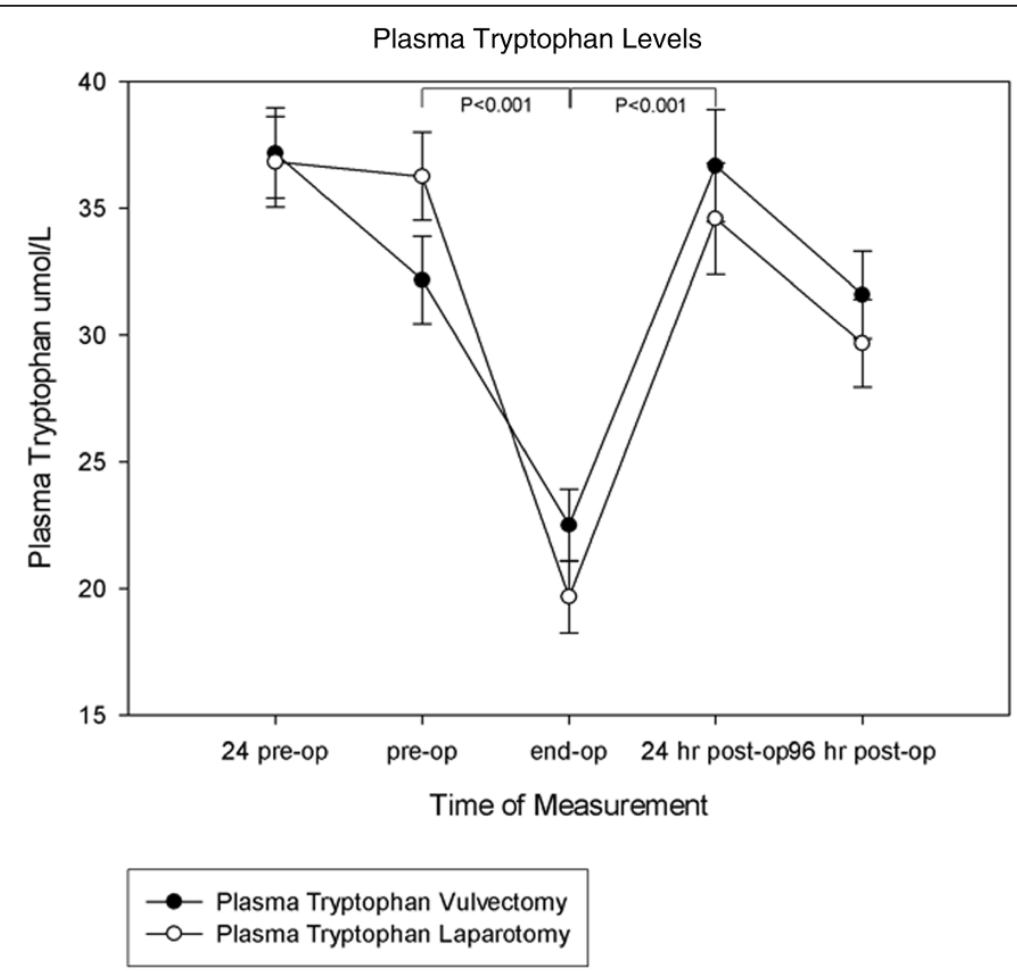

Significant within-subjrct effect, $\mathrm{P}<0.001$

Figure 2 The effect of anesthesia in patients undergoing vulvectomy and major abdominal surgery on perioperative levels of plasma tryptophan. Values are the mean and SEM. There was a significant within subject effect $(P<0.001)$. There was a significant decrease prior to induction and 30 minutes prior to the end of operation ( bracket $P<0.001$ ). A significant increase occurred 30 minutes prior to the end of operation and 24 hours post operative (bracket $\mathrm{P}<0.001$ ). 


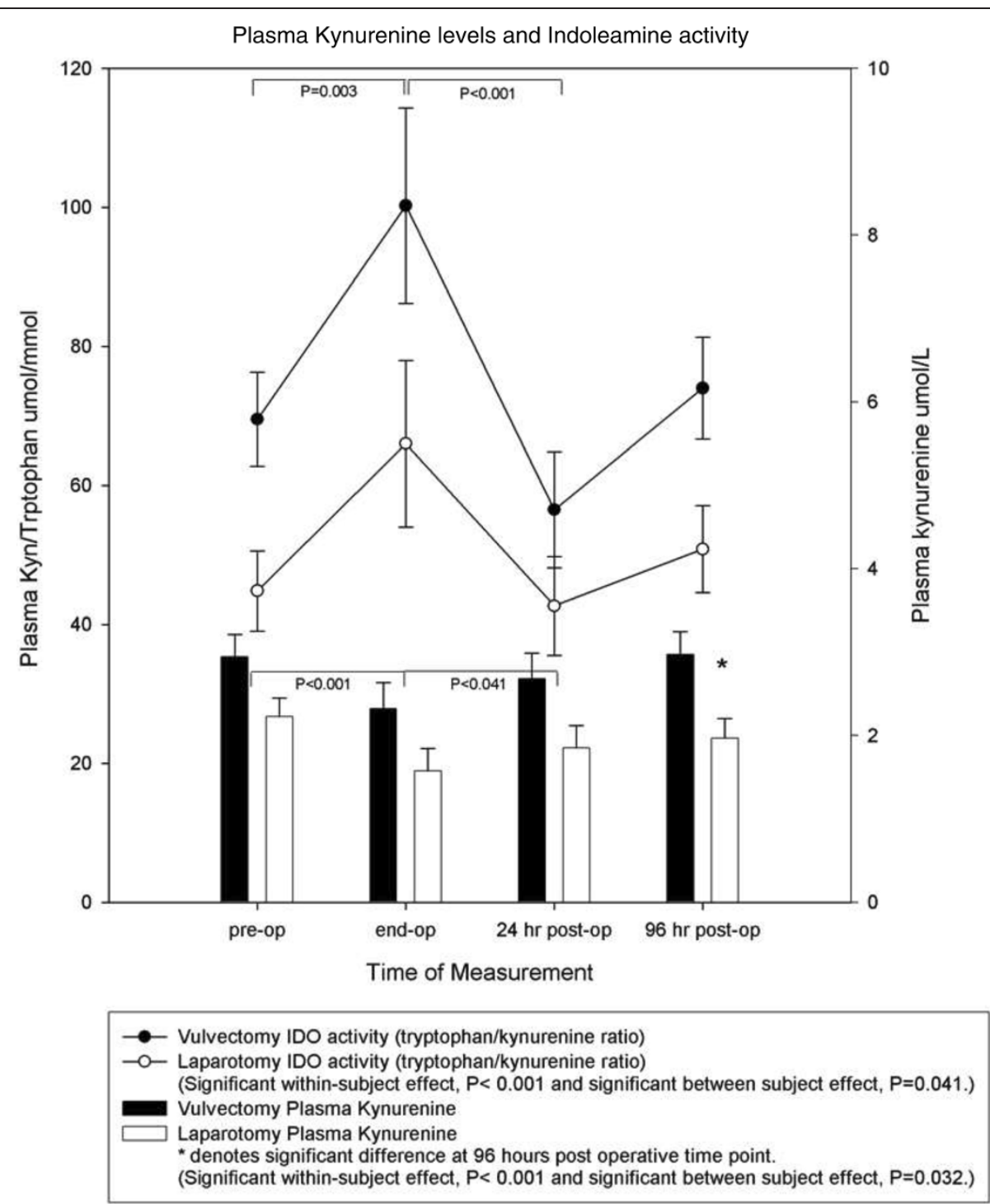

Figure 3 Line graph. The effect of anesthesia in patients undergoing vulvectomy and major abdominal surgery on perioperative IDO activity as defined by the ratio of tryptophan/kynurenine. Values are the mean and SEM. There was a significant within subject effect (P $<0.001)$. In addition, a significant difference between experimental groups was found $(P=0.041)$. There was a significant increase in plasma IDO activity measured prior to induction and thirty minutes prior to the end of the operation (bracket $\mathrm{P}=0.003$ ). A significant decrease occurred between IDO activity measured prior to the end of the operation and levels measured at 24 hours post operative (bracket $P<0.001$ ). Bar graph: The effect of anesthesia in patients undergoing vulvectomy and major abdominal surgery on perioperative levels of KYN. Values are the mean and SEM. There was a significant within subject effect $(P<0.001)$ as well as a significant difference between experimental groups $(P=0.032)$. At 96 hours post operative, the laparotomy group had significantly lower levels of plasma KYN than the vulvectomy group $(P=0.028)$. There was a significant plasma KYN level decrease during measurements made prior to induction and the end of operation (bracket $\mathrm{P}<0.001$ ). A significant increase occurred between points measured prior to the end of operation and 24 hours post operative (bracket $P<0.041$ ).

operation and 24 hours post operative might provide an explanation for the corresponding drop in IDO activity. Allowing for a negative feedback mechanism capable of maintaining KYN homeostasis, KYN suppresses the activation of $\mathrm{T}$ cells and NK cells which are responsible for IFN gamma secretion, one of the known factors responsible for activating IDO.

Neopterin is primarily produced by human monocytes and macrophages. Increased neopterin concentrations are indicative of cellular immune activation [19]. We found significantly higher levels of neopterin at all five time points in the vulvectomy group. The cancer necessitating vulvectomy may explain these higher levels because cancer has been correlated with higher neopterin levels [25,40]. It is clearly evident that the time curve relationship is nearly identical for both groups. Remarkably, anesthesia and surgery did not significantly dampen or increase neopterin levels. Instead, there seems to be a neopterin level drop 


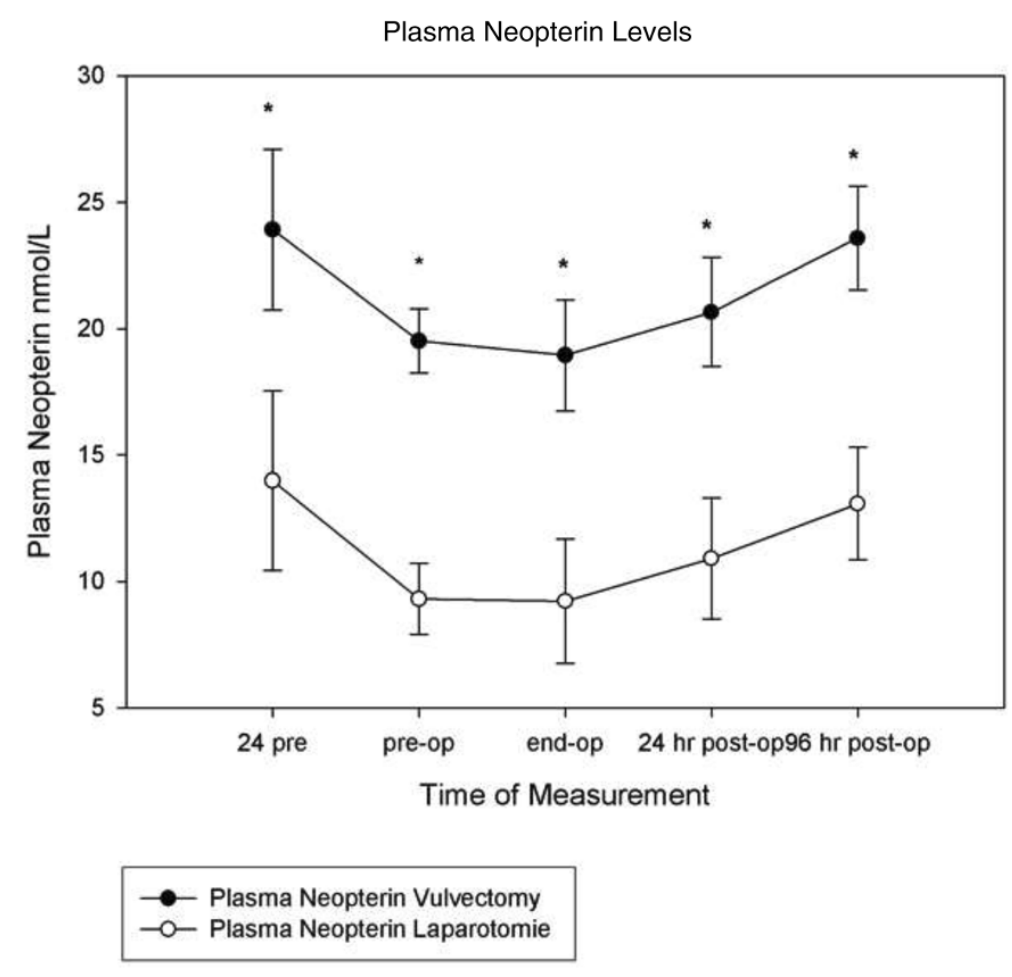

*Significant defference at all five time points Significant within-subject effect, $\mathrm{P}=0.033$

Significant between subject effect, $\mathrm{P}=0.005$

Figure 4 The effect of anesthesia in patients undergoing vulvectomy and major abdominal surgery on perioperative levels of plasma Neopterin. Values are the mean and SEM. There was a significant within subject effect $(P<0.033)$ and a significant difference between groups $(P=0.005)$.

during the 24 hour period prior to induction with a slower recovery to baseline level occurring during the 96 hour time period after surgery.

Not surprisingly, patients awaiting surgery suffer high levels of anxiety [41]. There is good evidence that in healthy individuals, acute psychological stress causes increased levels of catecholamines and cortisol, which in turn modulate the immune system [42-45]. We speculate that increased stress and associated increased cortisol synthesis prior to surgery caused a neopterin level decrease in the 24 hours prior to anesthesia. Opiod based anesthesia, however, is known to suppress cortisol synthesis and this may explain why neopterin levels do not continue to drop after induction of anesthesia $[38,46]$. Another explanation may be that the decrease in neopterin is counteracted by an increased release of neopterin induced by IFN $\gamma$.

Unlike our neopterin results, there are barely measurable IL-6 levels during the 24 hours prior to surgery. As would be expected from an acute phase pro-inflammatory cytokine known to be a sensitive early marker of tissue damage, there was a sharp increase resulting in significantly more IL- 6 being made in the major abdominal surgery group at the end of the operation compared to the vulvectomy group. It is noteworthy that at 96 hours post operative IL-6 levels almost return to baseline levels in both groups. The high prevalence of mast cells in the abdominal cavity might explain why an earlier and overwhelmingly more significant amount of IL-6 is released during the abdominal operation. A recent study provides convincing evidence that intestinal handling during open gynecological surgery causes mast cell activation and associated release of IL- 6 and other inflammatory mediators [47]. When comparing with neopterin results it is reasonable to conclude that the large IL-6 peak found in the major abdominal surgery group is due to the more severe surgical trauma and intestinal handling experienced by this group.

The course of the tryptophan kynurenine pathway measured in both groups suggests that activated IDO might buffer overzealous cellular immune system activation by allowing for the restoration of KYN levels [38]. The trend seen in our neopterin results supports this idea. While our IL-6 results confirm that major abdominal surgery causes a more acute activation of the cellular immune system when compared to the less invasive vulvectomy group, the 


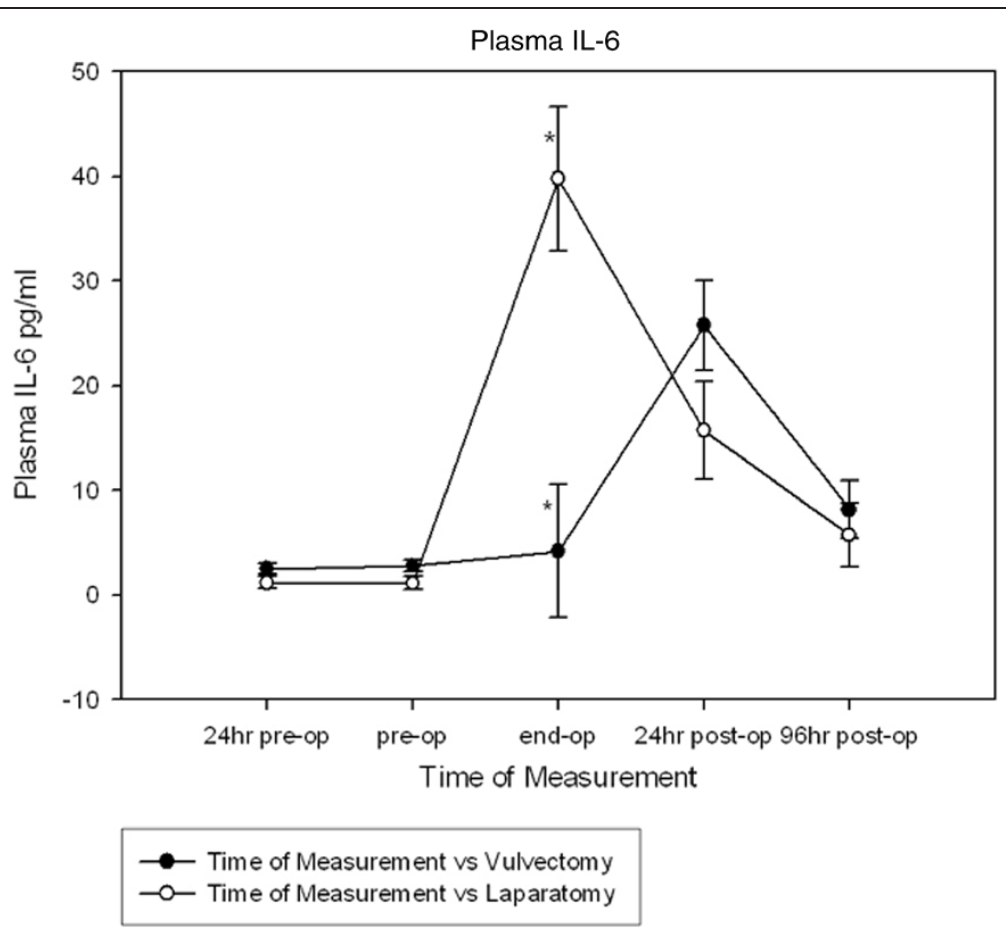

Figure 5 The effect of anesthesia in patients undergoing vulvectomy and major abdominal surgery on perioperative levels of plasma IL-6. There was a significant within subject effect $(P<0.001)$. The major abdominal surgery group had produced significantly more IL-6 then the vulvectomy group 30 minutes prior to the end of the operation $(P<0.001)$. ${ }^{*}$ Denotes significant difference at the end of operation time point, $\mathrm{P}<0.001$.

flare up seen in the major abdominal surgery group is short lived. This is confirmed by all of the data in this study. Between the end of the operation and 24 hours after surgery, the IL-6 peak quickly recedes to the same level seen in the less invasive (vulvectomy) group, while a significant kynurenine increase is seen. During this time frame, neopterin is still depressed when compared to baseline and 96 hour post operative levels.

In addition to its ability to suppress natural killer and $\mathrm{T}$ cells, kynurenine also has a vasodilating effect that might explain our results. It is likely that the vasodilating properties of propofol help depress kynurenine levels after induction. A recent study using animal models has found that kynurenine plays a similarly important role in determining arterial wall tonus as nitric oxide does [11]. The two mediators act redundantly to influence vascular tone [48-50].

Although this study is primarily intended to study the effects of differing degrees of surgery on inflammatory markers, this study also provides data that can be interpreted to show that anesthesia does not seem to be strictly immunosuppressive, but might have a buffering effect. It seems that adequate anesthesia preserves proper immune function while at the same time suppressing pathological immune activation in operations like major abdominal surgery which are more prone to a systemic inflammatory response syndrome (SIRS). Further research is necessary in order to investigate how opiates, hypnotic agents and the epidural technique specifically contribute to these effects. Most evidence suggests that opiates have immunomodulating properties, while propofol allows for proper function of the immune system [51-55]. It is noteworthy that in this study there was significantly more propofol used in the group expressing a significant IL-6 increase. Taking this into account, it is likely that propofol is not responsible for immunosuppression.

\section{Limitations}

The significantly less amount of propofol given to the vulvectomy group can be partly explained by the shorter operating time. However, women in this group were older and had higher ASA scores also explaining why less propofol was used. In addition, the greater amount of colloids and crystalloids given to the laparotomy group is related to the longer operating time and increased amount of blood loss in this group of patients. Nevertheless, the results shown in our figures make it clear that dilutional phenoma are not responsible for trends seen. Likewise, these peri-operative characteristics provide additional evidence that abdominal hysterectomy is a heavier, more traumatic operation in comparison to the vulvectomy procedure. The more severe nature of abdominal hysterectomy also explains why 
Table 4 Analgesia technique applied 24 hours post operative

\begin{tabular}{llll}
\hline & Only NSAIDs & $\begin{array}{l}\text { NSAIDs and } \\
\text { intravenous } \\
\text { morphine }\end{array}$ & $\begin{array}{l}\text { NSAIDs, intravenous } \\
\text { morphine and epidural } \\
\text { anesthesia }\end{array}$ \\
\hline Vulvectomy & 8 & 4 & 3 \\
Laparotomy* & 1 & 3 & 9 \\
\hline
\end{tabular}

*Laparotomy group had significantly more invasive pain control, $\mathrm{P}<0.05$.

anesthesiologists used significantly more invasive analgesia techniques during the 24 hour post operative period as seen in Table 4. Generally, a heavier regimen was chosen for heavier surgery. According to our results this seems to have an appropriate effect because IL-6 only showed one moment where levels were different between groups at 24 hours post operative.

Furthermore, we did not consider or note the menopausal status of women when conducting this study, however, if the menopausal status had a confounding effect it would make our results even stronger: From the literature we know, that after menopause, there is an increase in pro-inflammatory serummarkers (IL-6 and TNF-alpha) [56]. When taking age into account, our vulvectomy group would have had more women who were post-menopausal than in the abdominal hysterectomy group. However, we found the higher IL-6-levels in the abdominal hysterectomy, the group with the younger patients. This supports the claim that the effect of the procedure is stronger than changes due to aging.

One might also discuss, whether it is prudent, to use COX-2-inhibitors as analgetics in a study on inflammation processes. We decided to do so, because it reflects our clinical standard practice and it would be considered an ethical problem by our institutional Medica Ethics Committee to change our pain control procedures just to create better study conditions. There is growing evidence that the suppression of inflammatory processes by COX-2-antagonists has more than only analgetic effects: depression and the immune response in cancer patients are two of the most interesting fields [57-59]. We know that COX-2-inhibition can lead to down-regulation of IDO1 and decreased kynurenine levels [59]. However, in our study the dosages administered were not that extremely different and nevertheless the group with the higher total dose of COX2-inhibitor had the more pronounced changes in the immunological profile. Despite the use of a COX-2-inhibitor we found increased IDO-activity in both groups.

Finally, one might discuss the possible impact of the fact, that more patients in the abdominal hysterectomy used an epidural catheter . However, we know that an epidural catheter is not able to block the stress response to major surgery [60]. If the epidural anesthesia would have had an antiinflammatory effect, the differences between the groups might have even been bigger than observed in our study.
While taking all these factors into consideration, we are aware of the fact, that our groups are not totally similar. However, when there was a difference between patient demographics or in the anesthetic regimen used, they should have led to smaller differences than what were actually observed, which must be interpreted as extra evidence to support our theory.

\section{Conclusion}

We conclude that surgery and associated anesthesia cause a significant decrease in tryptophan levels, while significantly increasing IDO activity. Both types of surgery produce nearly identical neopterin time curve relationships, with no significant change occurring in either group. However, even though neopterin is unaffected by the severity of surgery, IL- 6 responded to surgical invasiveness by revealing a significant increase during major abdominal surgery.

\section{Competing interests}

The authors declare that they have no competing interests.

\section{Authors' contributions}

JWH: wrote the paper, data interpretation. RJS: design and coordination of study. DLS: statistical analysis. DF: Concept, design, analysis and coordination. All authors read and approved the final manuscript.

\section{Acknowledgements}

The authors wish to thank Claudia Heijmans-Antonissen, Freek Zijlstra, Ans Voskuilen-Kooyman and Marieke van der Heide-Mulder for their skilled technical and methodological assistance.

Project is funded by department research budget.

\section{Author details}

'Department of Anesthesiology, Erasmus Medical Center, PO Box 2040, 3000 CA, Rotterdam, The Netherlands. ${ }^{2}$ Department of Clinical Chemistry, Erasmus Medical Center, Rotterdam, the Netherlands.

Received: 14 May 2014 Accepted: 7 November 2014

Published online: 20 December 2014

\section{References}

1. Brix-Christensen V, Tonnesen E, Sorensen IJ, Bilfinger TV, Sanchez RG, Stefano GB: Effects of anaesthesia based on high versus low doses of opioids on the cytokine and acute-phase protein responses in patients undergoing cardiac surgery. Acta Anaesthesio/ Scand 1998, 42(1):63-70.

2. McBride WT, Armstrong MA, McBride SJ: Immunomodulation: an important concept in modern anaesthesia. Anaesthesia 1996, 51(5):465-473.

3. Salo M: Effects of anaesthesia and surgery on the immune response. Acta Anaesthesiol Scand 1992, 36(3):201-220.

4. Wirleitner B, Neurauter G, Schrocksnadel K, Frick B, Fuchs D: Interferongamma-induced conversion of tryptophan: immunologic and neuropsychiatric aspects. Curr Med Chem 2003, 10(16):1581-1591.

5. Grohmann U, Fallarino F, Puccetti P: Tolerance, DCs and tryptophan: much ado about IDO. Trends Immunol 2003, 24(5):242-248.

6. Carlin JM, Ozaki Y, Byrne Gl, Brown RR, Borden EC: Interferons and indoleamine 2,3-dioxygenase: role in antimicrobial and antitumor effects. Experientia 1989, 45(6):535-541.

7. Mellor AL, Munn DH: Tryptophan catabolism and T-cell tolerance: immunosuppression by starvation? Immunol Today 1999, 20(10):469-473.

8. Munn DH, Zhou M, Attwood JT, Bondarev I, Conway SJ, Marshall B, Brown C, Mellor AL: Prevention of allogeneic fetal rejection by tryptophan catabolism. Science 1998, 281(5380):1191-1193.

9. Frumento G, Rotondo R, Tonetti M, Damonte G, Benatti U, Ferrara GB: Tryptophan-derived catabolites are responsible for inhibition of $\mathrm{T}$ and 
natural killer cell proliferation induced by indoleamine 2,3-dioxygenase. J Exp Med 2002, 196(4):459-468.

10. Terness P, Bauer TM, Rose L, Dufter C, Watzlik A, Simon H, Opelz G: Inhibition of allogeneic $T$ cell proliferation by indoleamine 2,3dioxygenase-expressing dendritic cells: mediation of suppression by tryptophan metabolites. J Exp Med 2002, 196(4):447-457.

11. Wang Y, Liu H, McKenzie G, Witting PK, Stasch JP, Hahn M, Changsirivathanathamrong D, Wu BJ, Ball HJ, Thomas SR, Kapoor V, Celermajer DS, Mellor AL, Keaney JF Jr, Hunt NH, Stocker R: Kynurenine is an endothelium-derived relaxing factor produced during inflammation. Nat Med 2010, 16(3):279-285.

12. Heyes MP, Chen CY, Major EO, Saito K: Different kynurenine pathway enzymes limit quinolinic acid formation by various human cell types. Biochem J 1997, 326(Pt 2):351-356.

13. Grohmann U, Orabona C, Fallarino F, Vacca C, Calcinaro F, Falorni A, Candeloro P, Belladonna ML, Bianchi R, Fioretti MC, Puccetti P: CTLA-4-Ig regulates tryptophan catabolism in vivo. Nat Immunol 2002, 3(11):1097-1101.

14. Hansen AM, Driussi C, Turner V, Takikawa O, Hunt NH: Tissue distribution of indoleamine 2,3-dioxygenase in normal and malaria-infected tissue. Redox Rep 2000, 5(2-3):112-115.

15. Saito K, Markey SP, Heyes MP: Effects of immune activation on quinolinic acid and neuroactive kynurenines in the mouse. Neuroscience 1992, 51(1):25-39.

16. Fuchs D, Moller AA, Reibnegger G, Werner ER, Werner-Felmayer G, Dierich MP, Wachter $\mathrm{H}$ : Increased endogenous interferon-gamma and neopterin correlate with increased degradation of tryptophan in human immunodeficiency virus type 1 infection. Immunol Lett 1991, 28(3):207-211.

17. Melichar B, Solichova D, Freedman RS: Neopterin as an indicator of immune activation and prognosis in patients with gynecological malignancies. Int J Gynecol Cancer 2006, 16(1):240-252

18. Werner-Felmayer G, Werner ER, Fuchs D, Hausen A, Reibnegger G, Wachter $H$ : Neopterin formation and tryptophan degradation by a human myelomonocytic cell line (THP-1) upon cytokine treatment. Cancer Res 1990, 50(10):2863-2867.

19. Widner B, Leblhuber F, Fuchs D: Increased neopterin production and tryptophan degradation in advanced Parkinson's disease. J Neural Transm 2002, 109(2):181-189.

20. Fuchs D, Hausen A, Reibnegger G, Werner ER, Dierich MP, Wachter H: Neopterin as a marker for activated cell-mediated immunity: application in HIV infection. Immunol Today 1988, 9(5):150-155.

21. Radunovic N, Kuczynski E, Rebarber A, Nastic D, Lockwood CJ: Neopterin concentrations in fetal and maternal blood: a marker of cell-mediated immune activation. Am J Obstet Gynecol 1999, 181(1):170-173.

22. Wachter H, Fuchs D, Hausen A, Reibnegger G, Werner ER: Neopterin as marker for activation of cellular immunity: immunologic basis and clinical application. Adv Clin Chem 1989, 27:81-141.

23. Widner B, Baier-Bitterlich G, Wede I, Wirleitner B, Fuchs D: Neopterin derivatives modulate the nitration of tyrosine by peroxynitrite. Biochem Biophys Res Commun 1998, 248(2):341-346.

24. Hoffmann G, Wirleitner B, Fuchs D: Potential role of immune system activation-associated production of neopterin derivatives in humans. Inflamm Res 2003, 52(8):313-321.

25. Murr C, Fuith LC, Widner B, Wirleitner B, Baier-Bitterlich G, Fuchs D: Increased neopterin concentrations in patients with cancer: indicator of oxidative stress? Anticancer Res 1999, 19(3A):1721-1728.

26. Strohmaier W, Redl H, Schlag G, Inthorn D: D-erythro-neopterin plasma levels in intensive care patients with and without septic complications. Crit Care Med 1987, 15(8):757-760.

27. Bolke E, Jehle PM, Graf M, Baier A, Wiedeck H, Steinbach G, Storck M, Orth K. Inflammatory response during abdominal and thyroid surgery: a prospective clinical trial on mediator release. Shock 2001, 16(5):334-339.

28. Cruickshank AM, Fraser WD, Burns HJ, Van Damme J, Shenkin A: Response of serum interleukin- 6 in patients undergoing elective surgery of varying severity. Clin Sci (Lond) 1990, 79(2):161-165.

29. Demura S, Takahashi K, Kawahara N, Watanabe Y, Tomita K: Serum interleukin-6 response after spinal surgery: estimation of surgical magnitude. J Orthop Sci 2006, 11(3):241-247.

30. Jesch NK, Kuebler JF, Nguyen H, Nave H, Bottlaender M, Teichmann B, Braun A, Vieten G, Ure BM: Laparoscopy vs minilaparotomy and full laparotomy preserves circulatory but not peritoneal and pulmonary immune responses. J Pediatr Surg 2006, 41(6):1085-1092.
31. Shin TY, Kim SH, Choi CH, Shin HY, Kim HM: Isodon japonicus decreases immediate-type allergic reaction and tumor necrosis factor-alpha production. Int Arch Allergy Immunol 2004, 135(1):17-23.

32. Zhang $Y$, Ramos BF, Jakschik BA: Neutrophil recruitment by tumor necrosis factor from mast cells in immune complex peritonitis. Science 1992, 258(5090):1957-1959.

33. Wan H, Versnel MA, Leijten LM, van Helden-Meeuwsen CG, Fekkes D, Leenen PJ, Khan NA, Benner R, Kiekens RC: Chorionic gonadotropin induces dendritic cells to express a tolerogenic phenotype. J Leukoc Biol 2008, 83(4):894-901.

34. Widner B, Werner ER, Schennach H, Wachter H, Fuchs D: Simultaneous measurement of serum tryptophan and kynurenine by HPLC. Clin Chem 1997, 43(12):2424-2426.

35. Van Gool AR, Fekkes D, Kruit WH, Mulder PG, Ten Hagen TL, Bannink M, Maes M, Eggermont AM: Serum amino acids, biopterin and neopterin during long-term immunotherapy with interferon-alpha in high-risk melanoma patients. Psychiatry Res 2003, 119(1-2):125-132.

36. Heijmans-Antonissen C, Wesseldijk F, Munnikes RJ, Huygen FJ, van der Meijden P, Hop WC, Hooijkaas H, Zijlstra FJ: Multiplex bead array assay for detection of 25 soluble cytokines in blister fluid of patients with complex regional pain syndrome type 1. Mediators Inflamm 2006, 2006(1):28398.

37. Brand JM, Frohn C, Luhm J, Kirchner H, Schmucker P: Early alterations in the number of circulating lymphocyte subpopulations and enhanced proinflammatory immune response during opioid-based general anesthesia. Shock 2003, 20(3):213-217.

38. Brand JM, Schmucker P, Breidthardt T, Kirchner H: Upregulation of IFNgamma and soluble interleukin-2 receptor release and altered serum cortisol and prolactin concentration during general anesthesia. J Interferon Cytokine Res 2001, 21(10):793-796.

39. Werner ER, Hirsch-Kauffmann M, Fuchs D, Hausen A, Reibnegger G, Schweiger M, Wachter H: Interferon-gamma-induced degradation of tryptophan by human cells in vitro. Biol Chem Hoppe Seyler 1987, 368(10):1407-1412.

40. Schroecksnadel K, Winkler C, Fuith LC, Fuchs D: Tryptophan degradation in patients with gynecological cancer correlates with immune activation. Cancer Lett 2005, 223(2):323-329.

41. Jelicic M, Bonke B, Millar K: Clinical note on the use of denial in patients undergoing surgery for breast cancer. Psychol Rep 1993, 72(3 Pt 1):952-954.

42. Bachen EA, Manuck SB, Marsland AL, Cohen S, Malkoff SB, Muldoon MF, Rabin BS: Lymphocyte subset and cellular immune responses to a brief experimental stressor. Psychosom Med 1992, 54(6):673-679.

43. Marty J, Nimier M, Rocchiccioli C, Mantz J, Luscombe F, Henzel D, Loiseau A, Desmonts JM: Beta-adrenergic receptor function is acutely altered in surgical patients. Anesth Analg 1990, 71(1):1-8.

44. Page GG, Ben-Eliyahu S, Liebeskind JC: The role of LGL/NK cells in surgeryinduced promotion of metastasis and its attenuation by morphine. Brain Behav Immun 1994, 8(3):241-250

45. Roizen MF, Horrigan RW, Frazer BM: Anesthetic doses blocking adrenergic (stress) and cardiovascular responses to incision-MAC BAR. Anesthesiology 1981, 54(5):390-398.

46. Hoehe M, Duka T, Doenicke A: Human studies on the mu opiate receptor agonist fentanyl: neuroendocrine and behavioral responses. Psychoneuroendocrinology 1988, 13(5):397-408.

47. The FO, Bennink RJ, Ankum WM, Buist MR, Busch OR, Gouma DJ, van der Heide S, van den Wijngaard RM, de Jonge WJ, Boeckxstaens GE: Intestinal handling-induced mast cell activation and inflammation in human postoperative ileus. Gut 2008, 57(1):33-40.

48. Connelly L, Madhani M, Hobbs AJ: Resistance to endotoxic shock in endothelial nitric-oxide synthase (eNOS) knock-out mice: a proinflammatory role for eNOS-derived no in vivo. J Biol Chem 2005, 280(11):10040-10046.

49. Quaschning T, Voss F, Relle K, Kalk P, Vignon-Zellweger N, Pfab T, Bauer C, Theilig F, Bachmann S, Kraemer-Guth A, Wanner C, Theuring F, Galle J, Hocher B: Lack of endothelial nitric oxide synthase promotes endothelininduced hypertension: lessons from endothelin-1 transgenic/endothelial nitric oxide synthase knockout mice. J Am Soc Nephrol 2007, 18(3):730-740.

50. Thomas SR, Stocker R: Redox reactions related to indoleamine 2,3dioxygenase and tryptophan metabolism along the kynurenine pathway. Redox Rep 1999, 4(5):199-220.

51. Bayer BM, Daussin S, Hernandez M, Irvin L: Morphine inhibition of lymphocyte activity is mediated by an opioid dependent mechanism. Neuropharmacology 1990, 29(4):369-374. 
52. Devlin EG, Clarke RS, Mirakhur RK, McNeill TA: Effect of four i.v. induction agents on T-lymphocyte proliferations to PHA in vitro. Br J Anaesth 1994 73(3):315-317

53. Le Cras AE, Galley HF, Webster NR: Spinal but not general anesthesia increases the ratio of T helper 1 to T helper 2 cell subsets in patients undergoing transurethral resection of the prostate. Anesth Analg 1998 87(6):1421-1425.

54. Roy S, Cain KJ, Chapin RB, Charboneau RG, Barke RA: Morphine modulates NF kappa B activation in macrophages. Biochem Biophys Res Commun 1998, 245(2):392-396.

55. Salo M, Pirttikangas CO, Pulkki K: Effects of propofol emulsion and thiopentone on Thelper cell type-1/type-2 balance in vitro. Anaesthesia 1997, 52(4):341-344

\section{Submit your next manuscript to BioMed Central and take full advantage of:}

- Convenient online submission

- Thorough peer review

- No space constraints or color figure charges

- Immediate publication on acceptance

- Inclusion in PubMed, CAS, Scopus and Google Scholar

- Research which is freely available for redistribution 